\title{
Communicating risks of foodborne diseases
}

\author{
Tanja M. Wildemann* \\ Peter-Rosegger-Str. 15, 95447 Bayreuth, Germany
}

Received 7 December 2005; accepted 26 January 2006

\begin{abstract}
Foodborne diseases contribute substantially to the overall burden of disease, including hospitalizations, economic loss, and death. Nonetheless, in contrast to food safety experts, the public usually perceives foodborne diseases as low risk, which highlights the differences in the perception of the risk. Many studies have shown that risk perception is a complex concept determined by a variety factors. Among the factors associated with increased concern are high media attention and an impact on children.

Risk communication is a new concept aimed at the providing meaningful, relevant, and accurate information. The purpose is to increase knowledge and enable the recipients to make informed choices. The process of risk communication is complicated by the many contributors, including experts, lay people, risk managers, media, and other stakeholders. It is a two-way process that requires respecting and listening to the contributors. The risk message and its originator are crucial components that account for the success of risk communication.

Communication campaigns aim at raising awareness of hygienic food preparation at home, changing risk behavior, and reducing the number of foodborne infections. By considering the determinants of risk perception and the rules for communicating effectively, risk communication can help preventing foodborne infections and improve public health.

(c) Central European Science Journals Warsaw and Springer-Verlag Berlin Heidelberg. All rights reserved.
\end{abstract}

Keywords: Risk communication, risk perception, foodborne diseases

\section{Introduction}

In December 2003, the European Commission convened a conference entitled "Risk perception: Science, Public Debate and Policy Making" on public awareness of food safety issues. Food crises and scares referring to different kinds of food-related hazards have

* E-mail: tanja.wildemann@gmx.de 
increased public concern and decreased consumers' confidence in food regulators over recent years [1].

Microbiological hazards are most often characterized differently by the public and food safety experts, who include dieticians, epidemiologists, risk analysts, food producers, spokesmen of regulatory and advisory bodies, and government officials [2]. Although these experts rank the risk of microbiological hazards as very high, consumers attribute higher risk to food additives, pesticide residues, and contaminants [3].

A synopsis of surveillance data in the United States revealed the overall burden of foodborne diseases. Mead et al. estimated that foodborne diseases cause approximately 76 million illnesses, 325,000 hospitalizations and 5000 deaths each year. Only five pathogens are responsible for over $90 \%$ of the estimated food-related deaths: Salmonella (31 \%), Listeria (28\%), Toxoplasma (21\%), Norwalk-like viruses (7\%), Campylobacter (5\%) and Escherichia coli O157:H7 (enterohemorrhagic E. Coli [EHEC]) (3\%). Even though $E$. coli accounts for relatively few food-related deaths, it has a major impact on public health, including more than 60,000 illnesses, over 2000 hospitalizations, and over 62 deaths each year [4].

This article investigates the reasons why foodborne diseases and, in particular, infections by EHEC bacteria are perceived in a different way by lay people and experts, and it describes the elements of an effective risk communication program.

\section{Risk perception}

In developed countries, the taking of risk is not only an intrinsic part of life but also essential for economic and social development. Living involves risk; however, it is crucial to know what level of risk is acceptable to the public [5]. The Royal Society in London published a study group report defining risk perception as "the combined evaluation that is made by an individual of the likelihood of an adverse event occurring in the future and its likely consequences" [6]. Populations are not homogeneous, and subgroups have different societal perceptions and complex, multidimensional reactions to health risks. Furthermore, the environment is determined by social, political, psychological, economic, and technological factors [7].

The risk perception of experts is usually based on scientific findings, using a probalistic approach ("facts and numbers") to estimate risks. The result is that scientists, risk managers, and politicians often complain about lay people's lack of knowledge [8].

In the beginning of risk perception research, scientists assumed that closing the knowledge gap between experts and lay people would eliminate the conflicts between them. This assumes a simple, inverse causal relationship between knowledge and perceived risk - the less the knowledge, the higher the perceived risk. Empirical research, however, suggests that risk perception is more complex [8].

Psychological research has identified a variety of factors that influence the perception of risk [8]. These factors have not only an impact on the perception of the risk but also on its acceptance: 
Table 1 Qualitative factors affecting risk perception and evaluation.

\begin{tabular}{|c|c|c|}
\hline \multicolumn{3}{|c|}{ Qualitative factors affecting risk perception and evaluation } \\
\hline Factor & $\begin{array}{l}\text { Conditions associated with } \\
\text { increased public concern }\end{array}$ & $\begin{array}{l}\text { Conditions associated with } \\
\text { decreased public concern }\end{array}$ \\
\hline Catastrophic potential & $\begin{array}{l}\text { Fatalities and injuries } \\
\text { grouped in time and space }\end{array}$ & $\begin{array}{l}\text { Fatalities and injuries scat- } \\
\text { tered and random }\end{array}$ \\
\hline Familiarity & Unfamiliar & Familiar \\
\hline Understanding & $\begin{array}{l}\text { Mechanisms or process not } \\
\text { understood }\end{array}$ & $\begin{array}{l}\text { Mechanisms or process under- } \\
\text { stood }\end{array}$ \\
\hline Controllability (personal) & Uncontrollable & Controllable \\
\hline Voluntariness of exposure & Involuntary & Voluntary \\
\hline Effects on children & Children specifically at risk & $\begin{array}{l}\text { Children not specifically at } \\
\text { risk }\end{array}$ \\
\hline Effects manifestation & Delayed effects & Immediate effects \\
\hline $\begin{array}{l}\text { Effects on future genera- } \\
\text { tions }\end{array}$ & Risk to future generations & No risk to future generations \\
\hline Victim identity & Identifiable victims & Statistical victims \\
\hline Dread & Effects dreaded & Effects not dreaded \\
\hline Trust in institutions & $\begin{array}{l}\text { Lack of trust in responsible in- } \\
\text { stitutions }\end{array}$ & $\begin{array}{l}\text { Trust in responsible institu- } \\
\text { tions }\end{array}$ \\
\hline Media attention & Much media attention & Little media attention \\
\hline Accident history & $\begin{array}{l}\text { Major and sometimes minor } \\
\text { accidents }\end{array}$ & No major or minor accidents \\
\hline Equity & $\begin{array}{l}\text { Inequitable distribution of } \\
\text { risks and benefits }\end{array}$ & $\begin{array}{l}\text { Equitable distribution of risks } \\
\text { and benefits }\end{array}$ \\
\hline Benefits & Unclear benefits & Clear benefits \\
\hline Reversibility & Effects irreversible & Effects reversible \\
\hline Origin & $\begin{array}{l}\text { Caused by human actions or } \\
\text { failures }\end{array}$ & $\begin{array}{l}\text { Caused by acts of nature or } \\
\text { God }\end{array}$ \\
\hline
\end{tabular}

Source: National Research Council, 1989, p. 35.

Peter Sandman, an American expert in risk communication, describes these factors collectively as "outrage factors", which reflects his conclusion that "the risks that kill you are not necessarily the risks that anger and frighten you". Although experts mainly consider the hazard (mortality) of an agent, lay people include the outrage factors, resulting in major misunderstandings between the two groups. Lay people pay little attention to 
the hazard, and experts almost no attention to outrage [9]. Furthermore, in participatory Western democracies, nonexperts demand greater involvement in decision-making. Thus, food regulators must take into account the determinants that have an impact on the public's risk perception [10].

One important factor for risk perception is gender. Particular attention must be paid to this with respect to food safety issues. Women are still mainly responsible for meal planning, purchasing of food, and preparing the meals and are thus more concerned about foodborne diseases. An additional factor is the number and age of children living in the household. Food hazards are generally considered as more important by individuals with children [7].

Usually, foodborne illness will not evoke outrage among lay people because they are perceived as voluntary, controllable, visible, and familiar. This means that most individuals perceive the threats of foodborne diseases as low, although food can pose significant risks. In particular, foodborne illness originating in the home is perceived as familiar and controllable [11]; however, this picture changes for EHEC infections. These meet several conditions that are associated with increased concern. EHEC bacteria were first discovered in the 1980s, which makes them less familiar. During an outbreak, the number of victims is high, and those suffering from the severe complications (kidney failure) or death are identifiable. Additionally, children are among those at high risk, which attracts intense media attention, leading to headlines containing phrases such as "hamburger disease", "child killer" or "killer bacteria".

\section{Risk communication}

Risk communication evolved in the mid-1980s to address public communication problems regarding environmental problems. In general, the communication of risk is intuitively applied. Risk communication, however, is more than simply the dissemination of "risk" information. Rather, risk communication combines elements of conflict resolution, public participation, and two-way communication [12].

Emerging foodborne pathogens such as EHEC challenge existing means of safety communication and require a particular need for evaluation because of their novelty and ability to produce outbreaks in diverse places in the world and in the food chain. To prevent uncontrolled outbreaks, a communication strategy should be in place [13].

\section{The players}

The process of risk communication involves various groups, including experts, stakeholders, lay people and the media. All of these groups interact with each other.

The experts or risk assessors are responsible for objectiveness and professionalism and for providing the scientific basis for decisions made by, for example, policy makers; however, experts have their own interests and value systems so that their objectiveness is not completely independent [14]. To make decisions, policy- and decision-makers must iden- 
tify and weigh alternatives. The risk manager must consider various factors in addition to science. In particular, on a national level, he must include social, economic, religious, and ethical concerns. Interactive communication at all stages of the decision-making process is important to ensure transparency and consistency [15].

The fact that everyone is a layperson becomes obvious when conversing with an expert. A layperson estimates risk in a different way than an expert: laypeople consider current knowledge, motives, attitudes, emotions, and the social, political, and cultural environment. Other stakeholders involved in risk communication include nongovernmental organizations, industry, and lobbies [14].

Mass media plays the role of a transmitter in the risk communication process. In the beginning, there is the event and, on the receiving end, the public. A large audience can be reached through mass media, such as radio, magazines or television. They have their own rules, working procedures, and organization for how and about what they report [14]. Because we live an era in which we are exposed to information throughout the day, the question of how the media influences risk perception is fundamental. Although there is no doubt that the media has an impact on risk perception, it is uncertain whether a difference exists between intentional and unintentional risk information and how long the effect persists [16].

\section{$5 \quad$ Risk message originator}

The public is exposed to a variety of risk messages from different sources, such as governments, consumer organizations, research institutes, and the food industry. Therefore, it is important to keep in mind that the reception of a risk message depends also on the perception of the risk message originator. If the public does not consider the source credible, it will be difficult to convey the message and effect long-term changes in attitude. Credibility has two dimensions: expertise and trustworthiness. Expertise refers to the knowledge in a specific area and trustworthiness to the reliability of the message content $[2]$.

Trust has numerous dimensions, which makes it a complex concept that is impossible to predict by single items or psychological constructs [17]. Research indicates that trust depends on three factors: knowledge (i.e., expertise), honesty concerning the completeness of the provided information, and whether the concerns of the consumers are taken seriously by the risk message originator [18]. Trust plays a major role in the credibility and acceptance of an institution. Therefore, trust - or distrust - in risk managers influences the processing of risk information and potential changes in behavior [19].

Involving the media during the whole process may enhance the trust of the public in food safety policy. Continuous updates on research results and progress can help to show that words are followed by action [20]. In the same way, the public should participate in decision-making to increase the transparency and consistency of management decisions, to improve the effectiveness and efficiency of the overall process, and to strengthen trust and confidence of consumers in food safety policy [15]. 
To close the gap in risk perception between lay people and experts, it has been argued that the scientific knowledge of the general public should be increased; however, considering the amount of technical information and its complexity, it will be difficult to motivate the public to absorb it. For this reason, the public has to rely on and trust risk communicators to filter and disseminate relevant information so that it is understandable by lay people [17].

The perception of an information source is also highly dependent on the cultural background, and the culture defines the level of acceptable risk in a society. Neither scientists nor lay people can escape these cultural prejudices and attitudes [21].

\section{The risk message}

The risk message is a crucial component of risk communication. In 1989, the National Research Council defined a risk message as "a written, verbal, or visual statement containing information about risk; may or may not include advice about risk reduction behavior; a formal risk message is a structured written, audio, or visual package developed with the express purpose of presenting information about risk. Each risk message has an identifiable source and is addressed to one or more audiences."

In practice, depending on the food hazard, the messages will differ in their target group, appearance, statement, and sponsor types. Gordon [11] investigated the content of risk messages with respect to their stimulation of risk perception and self-efficacy as well as whether sponsorship is associated with a specific statement design. Riskstimulating statements, which foster the awareness of food-related risks, appeared most often. Calculation of the proportion of risk-stimulating to risk-reducing messages, which pacify risk perceptions of food-related risks, revealed a difference between statements made by private sponsors and governments. Whereas governments clearly favor riskstimulating messages, private sponsors use equal numbers of risk-stimulating and riskreducing messages. The study also found that self-efficacy statements, which focus on consumers' desire to change their behavior, are almost completely ignored. The author concluded that risk messages that aim at promoting safe food-handling practices should include content that (i) stimulates risk perceptions regarding foodborne illness and (ii) promotes feelings of competency that one can successfully adopt the proper food-handling behaviors. Another study found that consumers prefer the content of a risk message presented in a clear way and that includes risk and related uncertainties [22].

Risk messages need to address the concerns of the public. In general, research on food hazards has shown that the public is concerned about health and the risk of death. If a risk regulator fails to consider these concerns, he might risk that the risk message is ignored [23]

The development of risk messages is among the most difficult and time consuming tasks in risk communication. The message must be accurate and comprehensive. Also, each message must be personal, recognizing that individuals are unique, while general enough to reach every member of the target group, although expecting that they will 
respond to the message in their own ways [24]. A complete risk message contains the following components [26]:

- Information about the nature of risks;

- Information about the nature of benefits;

- Information on alternatives;

- Uncertainties in knowledge about risks;

- Information on management

The language or content of each risk message must be simple. Initially, the language should be simplified, whereas the content should only be simplified if necessary. Conveying complex information requires time. The content of the final message should include all the information need for the lay public to feel that they understand the context, to answer their questions, and to provide them with a "grid" to which they can add additional pieces of information when they arise. Considering in advance the message to be conveyed will help avoid its oversimplification. The core of the message should consist of explaining the risk itself, which can be done by using risk comparisons; however, it is important to use appropriate examples [27].

Policy makers have the responsibility of protect public health and are, therefore, entrusted with the power to make far-reaching decisions. The public, however, is mainly concerned with protecting their families and people they know personally, in other words "what is going to happen to my family?" This difference in perspective must be understood and considered for each risk message. Thus, the risk message should include more than pure technical data and should reduce abstraction to personalize the risk and help convey the message [9].

\section{$7 \quad$ Effective risk communication}

In a democracy, experts with specialized knowledge play an important role, but decisions are controlled by officials, generally nonspecialists, who must justify their decisions to the public [25].

Science starts with a hypothesis and attempts to confirm or invalidate it. Furthermore, science provides the basis for deciding whether a risk exists and therefore, needs to be addressed; however, research is a tedious process, and there is a high burden of proof for taking action [28]. There is inherent uncertainty to science, particularly if the knowledge about a given risk is incomplete, although this does not simply imply the absence of knowledge. Rather, it describes a situation of inadequate information, which can be of three sorts: inexactness, unreliability, and border with ignorance [29]. In science and risk analyses, uncertainty is always present and must be considered in the decision-making process.

Denying uncertainty in risk communication can result in a negative impact on public risk perception once the true extent of the problem is revealed (e.g., the handling of BSE in the UK) [30]. In response to such a change, the public can react with distrust and reduced public confidence in the activities of risk managers. Communicating gaps in the 
experts' knowledge could be perceived as 'telling the truth' and can contribute to an increase in credibility and trustworthiness of the institution presenting the information [29]. The difficulty is therefore to find the right balance between saying too much and too little. It is also important to consider scientific knowledge as well as citizens' values [16].

\section{The risk communication strategy}

Risk communication occurs in different contexts (e.g., crisis or noncrisis situations) and with different aims (e.g., warning, informing, or educating). Although the strategy for effective risk communication is always based on the same principles, the actual implementation may differ.

Generally, a risk communication strategy contains different components that can be grouped in a sequence according to the systematic approach of the entire process [31]:

- Background/information;

- Preparation/assembly;

- Dissemination/distribution;

- Review/evaluation

Effective risk communication will follow the seven cardinal rules of risk communication described by Covello and Allen [32]:

(1) Accept and involve the public as a partner.

Your goal is to produce an informed public, not to defuse public concerns or replace actions.

(2) Plan carefully and evaluate your efforts.

Different goals, audiences, and media require different actions.

(3) Listen to the public's specific concerns.

People often care more about trust, credibility, competence, fairness, and empathy than about statistics and details.

(4) Be honest, frank, and open.

Trust and credibility are difficult to obtain; once lost, they are almost impossible to regain.

(5) Work with other credible sources.

Conflicts and disagreements among organizations make communication with the public much more difficult.

(6) Meet the needs of the media.

The media are usually more interested in politics than risk, simplicity than complexity, danger than safety.

(7) Speak clearly and with compassion.

Never let your efforts prevent your acknowledging the tragedy of an illness, injury, or death. People can understand risk information, but they may still not agree with you; some people will not be satisfied.

The overall goal of risk communication is to provide meaningful, relevant, and accurate 
information to increase knowledge of the issue by all stakeholders. More specifically, the public gains a basic understanding of microbiological hazards in foods and ways to prevent foodborne infections, which will improve public health. Unnecessary food scares, which can make people stop eating specific products or a range of products, can be avoided [2].

\section{Successful risk communication}

A prerequisite of successful communication is that each group is willing to respect the opinions of and listen to all the other groups, making risk communication a two-way process [33].

When risk messages derive from a single source and the risk is assessed according to the specific criteria of the originator, it is more difficult to determine if the messages are successful.

One criterion for considering risk communication successful could be whether government officials, private organizations, and individuals were given sufficient information to make well-informed decisions and goal-directed individual choices. From this standpoint, risk communication raises the level of knowledge and gives those involved the feeling of being adequately informed within the limits of available knowledge [25]. Nevertheless, it is important to keep the following in mind:

- Successful risk communication does not always lead to better decisions.

- Successful risk communication might not result in a consensus about controversial issues or in uniform personal behavior;

- The recipient must be able to achieve as complete an understanding of the information as he desires.

\section{Obstacles to effective risk communication}

The risk communication process is complex and involves a number of people, which makes it necessary to pay special attention to issues hampering the success of risk communication.

Limited communication on an institutional and procedural level constitutes one category of obstacle. Decision-makers and scientists need to exchange information and to have a lively discussion on the strategy of how to effectively minimize foodborne risks [15]. Another category of obstacle involves issues of risk perception and the reception of risk messages by the public. There can be a variety of reasons that the message is not effectively conveyed, such as not or insufficiently addressing the real concerns associated with EHEC infections [23].

Risk communicators will often experience "optimistic bias", wherein people ignore the message if they perceive their own health not at risk [2]. This can also occur if an individual group within the population is not adequately addressed in a way that it feels addressed. An individual will also not respond to a risk message if he feels neither vulnerable to the hazard nor capable of controlling the risk [17]. 


\section{Conclusions}

Foodborne diseases are high on the public health agenda of an increasing number of countries. Among other things, this results in the implementation of surveillance programs. These programs facilitate the estimation of the contribution that foodborne diseases make to the overall burden of disease, and they provide a tool for calculating economic losses, which allows the impact of foodborne disease on the health of the public to be determined [23]

Research on food-related hazards has identified gaps in consumer knowledge regarding safe food-handling practices, for example in young men. The main factors responsible for outbreaks are food poisoning through improper preparation, handling, storage, and cross-contamination at home [34].

Foodborne illnesses, such as EHEC infections, can be prevented by appropriate behavior of individuals, and, therefore, communication campaigns aim at gaining food safety compliance in the home [35]; however, it is not enough just to convey the message to conduct hygienic processing of food at home, which is the scientific content of the message. The message must also directly address the groups at risk, considering their concerns and their individual and societal perceptions. Risk message originators must be aware of the variety of factors that influence the perception of risk and attitudes of lay people so that they can convey the message properly and induce a change in behavior. Although the concept of risk perception and the risk communication process are complex, using risk communication as a public health tool can help prevent and reduce the overall burden of foodborne diseases.

\section{References}

[1] D. Byrne: "Irrational fears or legitimate concerns - Risk perception in perspective", In: Speech at Risk perception: Science, Public Debate and Policy making conference, Brussels, 4 December 2003, (unpublished).

[2] J. Hansen, L. Holm, L. Frewer, P. Robinson and P. Sandøe: "Beyond the knowledge deficit: recent research into lay and expert attitudes to food risks", Appetite, Vol. 41, (2003), pp. 111-121.

[3] P. Sparks and R. Shepherd: "Public Perceptions of food - related hazards: Individual and social dimensions", Food Qual. Prefer., Vol. 5, (1994), pp. 185-194.

[4] P.S. Mead, L. Slutsker, V. Dietz, L.F. McCaig, J.S. Bresee, C. Shapiro, P.M. Griffin and R.V. Tauxe: "Food-related illness and death in the United States", Emerg. Infect. Dis., Vol. 5, (1999), pp. 607-625.

[5] M.A. Cañete: "Speech", on EU conference Risk perception: Science, public debate and policy making, Brussels 4 - 5 December 2003, (unpublished).

[6] The Royal Society: "Risk assessment: a study group report", 1983, p. 94.

[7] D.M. Dosman, W.L. Adamowicz and S.E. Hrudey: "Socioeconomic determinants of health- and food safety-related risk perceptions", Risk Anal., Vol. 21, (2001), pp. 
$307-317$.

[8] H. Schütz, P.M. Wiedemann and P.C.R. Gray: "Risk perception beyond the psychometric paradigm", Arbeiten zur RisikoKommunikation, Vol. 78, (2000), Forschungszentrum Jülich, http://www.fzjuelich.de/mut/publikationen/liste_riko.html

[9] P.M. Sandman: "Risk communication: Facing public outrage", EPA Journal, (1987), pp. 21-22.

[10] D.A. Powell: "Food safety and the consumer - perils of poor risk communication", Can. J. Anim. Sci., (2000), Vol. 80, pp. 393-404.

[11] J. Gordon: "Risk communication and foodborne illness: message sponsorship and attempts to stimulate perceptions of risk", Risk Anal., Vol. 23, (2003), pp. 1287-1296.

[12] E. Aakko: "Risk communication, risk perception, and public health", Wisc. Med. J., Vol. 103, (2004), pp. 25-28.

[13] B. Fischhoff and J.S. Downs: "Communicating Foodborne Disease Risk", Emerg. Infect. Dis., Vol. 3, (1997), pp. 489-495.

[14] O.P. Obermeier: Die Kunst der Risikokommunikation, Gerling Akademie Verlag, 1999, pp. 74-93.

[15] FAO/WHO: "The application of risk communication to food standards and safety matters", Report of a Joint FAO/WHO Expert Consultation', Rome, 2-6 February 1998, FAO Food and Nutrition Paper 70.

[16] A. af Wåhlberg and L. Sjöberg: "Risk perception and the media", J. Risk Res., Vol. 3, (2000), pp. 31-50.

[17] L.J. Frewer, C. Howard, D. Hedderly and R. Shepherd: "What determines trust in information about food-related risks? Underlying psychological constructs", Risk Anal., Vol. 16, (1998), pp. 473-486.

[18] S. Rosati, A. Saba: "The perception of risks associated with food-related hazards and the perceived reliability of sources of information", Int. J. Food Sci. Tech., Vol. 39, (2004), pp. 491-500.

[19] R.J. Eiser, S. Miles and L.J. Frewer: "Trust, perceived risk and attitudes toward food technologies", J. Appl. Soc. Psychol., Vol. 32, (2002), pp. 2423-2433.

[20] K. Blaine and D. Powell: "Communication of food-related risks", J. Agrobiotech. Manag. Econ., Vol. 4, (2001), pp. 179-185.

[21] M. Korthals: "Ethics of differences in risk perception and views on food safety", Food Protect. Tr., Vol. 24, (2004), pp. 498-503.

[22] WHO: "Foodborne surveillance", http://www.who.int/foodsafety/foodborne_disease/surveillance/en/, (Last visited: 7 Dec 05).

[23] D. Powell: "An Introduction to Risk Communication and the Perception of Risk", http://sginrm.ntpu.edu.tw/yml/download/risk04/risk-review.pdf, (Last visited: 7 Dec 05).

[24] P.M. Sandman: "Explaining risk to non-experts: a communications challenge", Emergency Preparedness Digest, (1987), pp. 25-29. 
[25] National Research Council: Improving Risk Communication, National Academy Press, Washington, D.C., 1989, pp. 26-32.

[26] National Research Council: Improving Risk Communication, National Academy Press, Washington, D.C., 1989, p. 175.

[27] R. Macfarlane: "Integrating the consumer interest in food safety: the role of science and other factors", Food Policy, Vol. 27, (2002), pp. 65-80.

[28] W.E. Walker, P. Harremoes, J. Rotmans, J.P. van der Sluijs, M.B.A. van Asselt, P. Janssen and M.P. Krayer von Krauss: "Defining Uncertainty: A Conceptual Basis for Uncertainty Management in Model-Based Decision Support", Integrated Assessment, Vol. 4, (2003), pp. 5-17.

[29] S. Miles and L.J. Frewer: "Public perception of scientific uncertainty in relation to food hazards", J. Risk Res., Vol. 6, (2003), pp. 267-283.

[30] L.J. Frewer, S. Miles, M. Brennan, S. Kuznesof, M. Ness and C. Ritson: "Public preferences for informed choice under conditions of risk uncertainty", Public Underst. Sci., Vol. 11, (2002), pp. 363-372.

[31] H-D, Werlein and K. Gerlach: "Enterohämorrhagische E. coli (EHEC)", http://www.harnisch.com/hygiene_report/Enterohaemorrhagische\%20E\%20coli.pdf, (Last visited: 7 Dec 05).

[32] V.T. Covello and F.H. Allen: Seven Cardinal Rules of Risk Communication. Pamphlet, U.S. E.P.A., Washington, DC, April 1988.

[33] O. Renn: "Perception of risks", Toxicol. Lett., Vol. 149, (2004), pp. 405-413.

[34] S. Miles, D.S. Braxton and L.J. Frewer: "Public perceptions about microbiological hazards in food", Brit. Food J., Vol. 101, (1999), pp. 744-762.

[35] S. Miles and L.J. Frewer: "Investigating specific concerns about different food hazards", Food Qual. Prefer., Vol. 12, (2001), pp. 47-61. 